\title{
Quando a Cidade Faz Esquina com a Escrita
}

\author{
Antônio Torres (Den Clube)
}

\begin{abstract}
A fronteira crepuscular entre o sono e a vigília era, neste momento, romana: fontes salpicando e ruas estreitas com arcos. A dourada e pródiga cidade de flores e pedra polida pelos anos. Às vezes, em sua semiconsciência, estava outra vez em Paris, ou entre escombros de guerra alemães, ou esquiando na Suíça e num hotel entre a neve. Algumas vezes, também, era um barbeiro da Geórgia, certa madrugada em casa. Era Roma esta manhã, na região sem tempo dos sonhos.
\end{abstract}

Carson McCullers, O Transeunte

Das cidades de sonho dos contos orientais às descritas por Marco Polo em $O$ Livro das Maravilhas, das "invisíveis" de Ítalo Calvino à visibilíssima do nosso Paulo Lins, a civitas, ou polis, ou urbe, sempre foi, é e sempre será um espaço para fabulações. "Continente das experiências humanas, com as quais está em permanente tensão, como ambiente construído, como necessidade histórica, ela é o resultado da imaginação e do trabalho coletivo do homem que desafia a natureza," no dizer de Renato Cordeiro Gomes, autor de Todas as Cidades, a Cidade. Eis aí o seu real significado para os escritores: um laboratório. De aprendizagem, experimentações, riscos, alegrias, decepções, inseguranças, ralações, derrapagens, trombadas - com quem você bateu de frente, hoje? -, frivolidades, "papo urbano e impopular" (copyright para o finado Scott Fitzgerald), papo cabeça, papo Jesus, medo, terror, competições, ultrapassagens. É pegar isso e bater no liquidificador. Como quem pega um limão e faz a limonada.

Edmund Wilson, o crítico literário norte-americano que sempre soube o que dizia, disse uma vez que só existem três personagens na literatura ocidental.

Primeiro: o que vai do campo para a cidade e se deixa seduzir por ela.

Segundo: o que faz o mesmo percurso, não se encanta com a cidade e volta para a sua aldeia. 
Terceiro: o da cidade.

Donde podemos concluir que, se a cidade dá espaço para a escrita, esta lhe dá voz. E constrói-lhe o mito.

Já desconfiava disso muito antes de ler Edmund Wilson. Nasci na roça. Mas com a cabeça, a alma e o coração povoados de cidades.

Há a Cidade Eterna, a Cidade Santa (Jerusalém, para uns, Meca, para outros), a Cidade Maravilhosa, a Grande Maçã, a Santa Maria Reina de los Angeles e a Santa Maria de Belém do Grão Pará, a de São Salvador e a de Saint-Georges de l'Oyapock, na fronteira da França com o Amapá, onde diariamente crianças brasileiras atravessam um rio largo e profundo para estudar francês, na esperança de um dia poderem trocar o verde e vago mundo da selva amazônica pelo spleen da Cidade Luz.

Reais ou imaginárias, há as utópicas, as que têm alma, as bonitas e as feias, as alegres e as tristes, as invictas, as heróicas, as complexas (São Paulo, por exemplo), as pobres de dar dó e as com a voz cheia de dinheiro (São Paulo também, para os nordestinos), as hospitaleiras e as que convém nem passar perto, as de paz (como o Rio) e as de guerra (idem), as onde o Judas perdeu as botas ou o vento faz a curva, as que nunca viram uma gota de chuva (Lima, Peru), as habitadas por fantasmas, como uma chamada Comala, inventada pelo mexicano Juan Rulfo em "Pedro Páramo," sem esquecer "A cidade do desassossego," de Gogol, "A cidade de vidro," de Paul Auster, a "Cidade perdida" e a "Babilônia revisitada," do já citado Scott Fitzgerald, que me fez conhecer o bar do Ritz, onde nunca estive, em Paris, cidade, aliás, que o leitor aqui já conhecia antes de pôr os pés lá, graças às páginas de Hemingway, Henry Miller, Proust e Boris Vian. Para nós, os leitores, que importância teria Praga sem Kafka, e Dublin sem James Joyce? Se o Rio de Machado de Assis não existe mais (no entanto é preciso lê-lo, para sabê-lo), Rubem Fonseca nos coloca cara a cara com a sua alta voltagem contemporânea.

Agora, as outras que me perdoem, mas lendária mesmo foi Axuhy, a cidade dos escravos fugidos como protesto à desumanidade do chicote de seus ferozes senhores, e que se tornaram muito ricos graças às audácias de seus saques. A lenda transformou-a num quilombo encantado, lá para as bandas dos campos da Lagarteira, perto das imensas dunas brancas dos Lençóis Grandes, às margens da lagoa do Caço, ao leste da capitania do Maranhão. Era uma das muitas fábulas que corriam sobre os negros fugitivos. E acabou se tornando um dos episódios mais patéticos da história colonial portuguesa no Brasil. Quem contou isso foi Viriato Correa, em seu livro "Terra de Santa Cruz." 


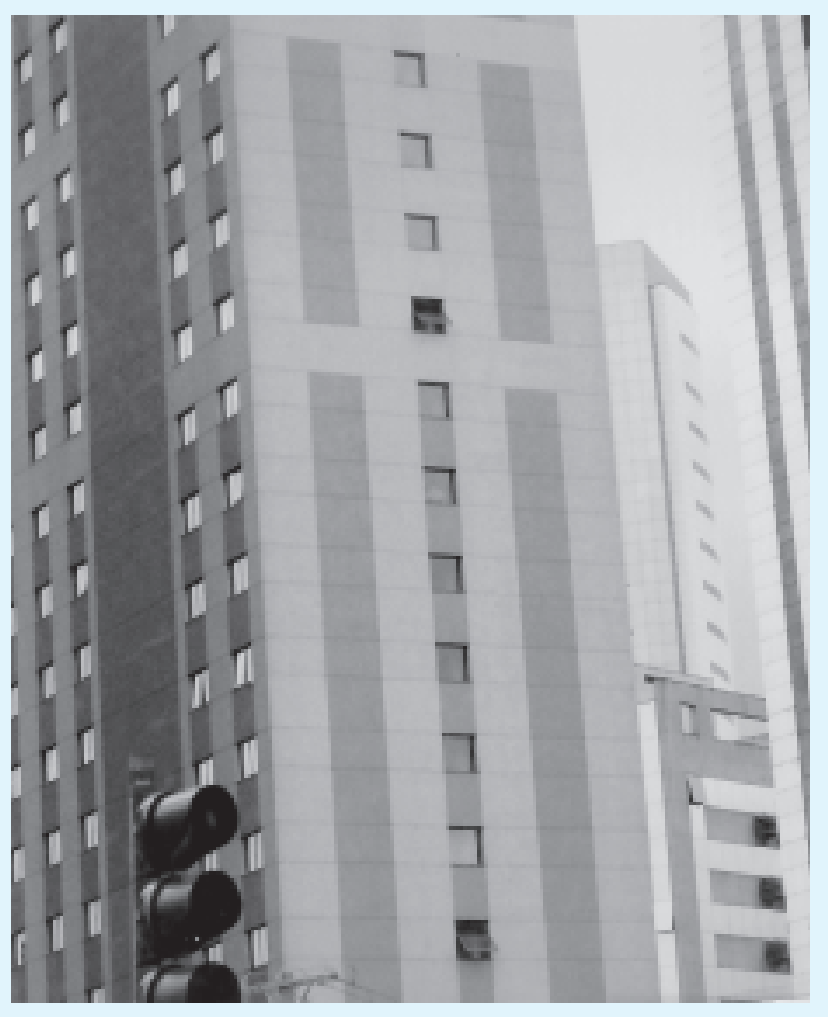

O tenente-coronel João Paulo Carneiro tinha um escravo, o Nicolau, que mentia pelos cotovelos. Por isso vivia no tronco, de lombo retalhado pelo chicote. Mal saía do castigo, voltava a mentir. E de novo era castigado.

Um dia o negro Nicolau conseguiu fugir. Passou-se muito tempo sem que ninguém lhe pusesse as mãos.

Numa noite do ano de 1794, ele voltou a São Luís, mesmo sabendo que se fosse apanhado ia levar uma surra de esfolar o couro.

Na manhã seguinte, quando o governador Fernando Antônio de Noronha saía de seus aposentos no palácio, deu de cara com o Nicolau, que se ajoelhou aos seus pés, implorando-lhe que o livrasse da morte. E narrou-lhe uma história fantástica.

Fugindo do chicote do coronel João Carneiro, ele embrenhara-se pelas matas adentro do rio Munim, no rumo dos quilombados da Lagarteira. Seria verdade ou mentira o afamado mocambo dos negros? Depois de muitos dias amargos, perdido entre os cerrados, oh, beleza!, oh alegria! Inesperadamente, acabou entrando na cidade de Axuhy, escondida num bosque, às margens frescas da lagoa do Caço. 
Os olhos do governador - que Viriato Correa descreve como uma soleníssima cavalgadura - brilhavam. E como era a cidade de Axuhy?

- Perto dela São Luís é uma pobre aldeia - respondeu-lhe Nicolau, com todo o encanto e poder de convencimento dos grandes mentirosos.

Prosseguiu:

Não havia na capital maranhense uma única rua como as muitas que vira em Axuhy, cheias de palácios, de ponta a ponta. Não havia ali nenhuma igreja comparável à da cidade dos campos da Lagarteira, não só pelo tamanho como pela riqueza. No altar-mor do templo de Axuhy erguia-se uma imagem da Virgem da Conceição, toda ela de ouro maciço.

- De ouro maciço? - o governador perguntou-lhe, de olhos arregalados.

- Sim, senhor. De ouro maciço e do tamanho de uma mulher bem alta.

E isso não era tudo. Em Axuhy não havia ninguém pobre. Lá, andava-se pelas ruas pisando em ouro e prata. $\mathrm{O}$ mais inferior de seus habitantes tinha arcas e arcas abarrotadas de moedas. E tanta era a riqueza da cidade, que a água da lagoa era bebida em cuias de ouro. Havia lá um padre jesuíta que cuidava da igreja. Os negros faziam negócios ocultos com os figurões de São Luís. E estes já sabiam que ele, o Nicolau, havia estado lá. Receiosos de que o segredo fosse revelado, queriam matá-lo. Só lhe restava a esperança de que o governador o salvasse.

E então, naquele exato momento, dom Fernando Antônio de Noronha, fidalgo, tenente-coronel do regimento da corte portuguesa, membro do conselho da rainha e governador do Maranhão, traçou um plano. Ia enviar um contingente militar para a conquista da fabulosa cidade. Nicolau ia ser o guia e um dos comandantes do seu exército, na caça ao tesouro de Axuhy. $\mathrm{O}$ escravo fugitivo foi nomeado capitão de milícias, imediatamente. Saiu do palácio fardado, com espada à cinta e penacho. Atrás dele, vinha o seu ordenança, guardando a devida distância do altivo chefe.

São Luís inteira caiu na gargalhada.

Ele não ligou. Nem o governador deu ouvidos a quem lhe lembrava da fama de mentiroso de Nicolau. Dom Fernando Antônio tinha pressa em armar dois mil homens, entre tropa de linha, milícias, pedestres e índios de serviço. Com tanta providência a tomar, não ia perder tempo com os fofoqueiros.

Enquanto isso o negro ia à forra. Deixou de falar com os seus iguais. Agora, com empáfia na voz e na figura, apertava a mão dos brancos na rua, abraçando as autoridades condescendentemente. Pôs-se a prender muita gente boa, a pretexto de comércio oculto com os negros de Axuhy. São Luís passou a temê-lo. Nicolau come- 
çou a ser convidado para festas e banquetes, nas casas dos ricos. Sentava-se à mesa como um figurão, bebia e comia do bom e do melhor e depois passava à sala, para conversar e namorar as moças brancas. E cada vez mais ganhava a confiança do governador, de quem se tornara o mais importante de seus auxiliares.

No dia 3 de agosto de 1794, a cidade de São Luís assistiu ao espetáculo imponente do embarque das tropas, divididas em dois grupos: um, tendo Nicolau como guia, seguiu por terra, pelas margens do rio Munim, com o negro falando muito e animando a todos na longa marcha. O outro ia pelo mar. Mas, na véspera de avistarem os campos da Lagarteira e formarem fileiras para o ataque a Axuhy, ninguém mais viu Nicolau. Procuraram por ele durante três dias. Em vão. Nicolau havia fugido. As tropas se perderam na mata, vencidas pela fome e o cansaço. Ainda assim acabaram por acertar o caminho de volta, mortas de vergonha. O desembarque em São Luís foi feito à noite, às escondidas, nas praias mais escuras.

E era uma vez Axuhy, a cidade coberta de ouro.

O governador, porém, não se deu por vencido.

Em seu relato à corte portuguesa sobre a volta das tropas, alegou que "depois de fazerem o seu passeio com todas as regras da tática, elas se haviam recolhido por não ser própria a estação, produzindo o passeio, apesar disso, um grande efeito moral."

A brincadeira do Nicolau custou-lhe caro. Anos depois, o seu antigo senhor o prendeu, trancafiando-o numa prisão perpétua.

Não, não foi ele quem inventou a lenda da cidade encantada. Mas deu-lhe brilho. Como um narrador memorável. Um mentiroso genial.

O espaço da cidade é o da fábula, da memória, da história, do mapa, da arte, da moda, da biografia, do trabalho, do estudo, do vizinho, do lazer, do sonho de quem nasceu no campo, da violência etc.

Surgida na Suméria no terceiro milênio a.C., ela viria a aglomerar a população num núcleo urbano e organizá-lo num conjunto político e econômico. Foram, porém, os antigos gregos que lhe deram uma estrutura acabada, permitindo o surgimento de uma florescente civilização, entre o VII e o IV séculos a.C. Na Antigüidade, o seu assentamento se fazia a partir de um ponto fortificado, como medida de defesa. $\mathrm{Na}$ Idade Média e nos Tempos Modernos, a Europa conhece o esplendor das cidades flamengas, alemãs, italianas etc. As metrópoles do mundo - Londres, Paris, Nova York, Tóquio, Moscou - chegam ao apogeu na era industrial, que faz o homem do campo marchar para a cidade, num fluxo migratório que nunca mais iria ter fim. Hoje, 
são cerca de duzentas cidades com mais de um milhão de habitantes, e mais de vinte acima dos 5 milhões, boa parte delas na América Latina (Cidade do México, São Paulo, Rio de Janeiro, Buenos Aires), Ásia (Xangai, Calcutá, Bombaim, Déli, Karachi) e África (Cairo, Lagos, Kinshasa). O mundo se torna cada vez mais urbano e a urbe um espaço problemático: já não há lugar para todos.

$\mathrm{E}$ aqui chegamos ao nosso tempo.

Esta é a estória. Ia um menino, com os Tios, passar dias no lugar onde se construía a grande cidade. Era uma viagem inventada no feliz; para ele produzia-se em caso de sonho. Saíam ainda com o escuro, o ar fino de cheiros desconhecidos. A Mãe e o Pai vinham trazê-lo ao aeroporto. A Tia e o Tio tomavam conta dele, justinhamente. Sorriase, saudava-se, todos se ouviam e falavam. O avião era da Companhia, especial, de quatro lugares. Respondiam-lhe a todas as perguntas, até o piloto conversou com ele. $\mathrm{O}$ vôo ia ser pouco mais de duas horas. O menino fremia no acorçôo, alegre de se rir para si, confortavelzinho. A vida podia às vezes raiar numa verdade extraordinária. Mesmo o afivelarem-lhe o cinto de segurança virava forte afago, de proteção, e logo novo senso de esperança: ao não-sabido, ao mais.

E esta é uma história facilmente identificável, tanto quanto a grande cidade que "apenas começava a fazer-se, num semi-ermo, no chapadão," pois saímos da leitura de "As Margens da Alegria", o conto magistral de João Guimarães Rosa, certos de que se trata da construção da nova capital do País, cujo princípio, aos olhos daquele menino, foi o caos. Ao descer do seu "móvel mundo," ele iria defrontar-se com um cenário de destruição e morte da fauna e flora. Um espaço em desencanto, onde tudo "perdia a eternidade." O sonho, a esperança - não era o que Brasília representava? anuviavam-se na poeira, reduzidos a pontos de interrogação, "no seu pensamentozinho, ainda na fase hieroglífica."

Metaforicamente recorro aqui ao engenho e arte de Guimarães Rosa para tentar dizer alguma coisa sobre o sonho modernizante deste País, a partir da era JK, quando governar era construir cidades e abrir estradas. Quando tínhamos todos de trocar a lida agrária pela vida urbana, a enxada pelos andaimes dos arranha-céus, o arado pelas britadeiras, o carro de bois pelos caminhões, o jegue e o cavalo pelos automóveis, a casa de sopapo e de alvenaria pelos barracos nas favelas, o candeeiro pela lâmpada, o pote d'água pela torneira, a rede pelo colchão de molas, o trabalho sem vínculo empregatício pela carteira assinada, a solidão dos ermos sertões pelo enxame das ruas; era deixar para trás o mundo arcaico e subir num pau-de-arara, com destino ao progresso, à civilização. De preferência, em São Paulo-Paraná. Melhor ainda: no ABC 
paulista, onde se construía o Brasil móvel, o nosso sonho movido a gasolina e óleo diesel.

Parece que foi ontem. E foi. Eu me recordo.

Meninos, eu vi a chegada do primeiro caminhão. O impacto foi maior do que as imagens na TV do homem pisando na Lua.

Primeiro, foi a visão fantasmagórica de dois imensos olhos acesos que apontaram de repente na Ladeira Grande. Depois, a inquietação para saber-se de que se tratava o estranho objeto luminoso, mais amedrontador do que o fogo-fátuo, pois roncava e emitia sons de um instrumento musical desconhecido naquelas brenhas fon-fon -, aumentando de intensidade à medida em que o objeto não-identificado se aproximava. E ele chegou mesmo, como um celerado. Volumoso, poderoso, assombroso. Mas temente a Deus, pois passou a tocar um bendito: "Louvando a Maria, o povo fiel..." Parecia querer anunciar-se como um enviado dos céus.

Para o menino desta história, foi um Deus-nos-acuda. Pedi pernas para correr e me esconder daquela assombração, muito mais apavorante do que as histórias de zumbis, lobisomens, mulas sem-cabeça, boitatás, almas penadas, gralhas mal-assombradas.

Na manhã seguinte lá estava ele, repousando debaixo de uma árvore. Grandão e perigoso. Mesmo de longe o bicho dava medo. Mantendo distância, aos poucos o menino foi se informando do que se tratava. Mas só fui me dar conta da revolução que a chegada do caminhão causara àquele remoto sertão muito tempo depois.

Ele espalhou nos nossos ares o cheiro da gasolina. As garotas do lugar endoideceram. Ninguém ali cheirava igual ao motorista do caminhão. Nem se vestia do seu jeito e falava ao seu modo. Tabaréus da roça, nunca mais. Agora elas ficavam de olho na Ladeira Grande, esperando algum rapaz da cidade. Humilhados e ofendidos, nós, os indesejados rapazes da roça, assim que vestíamos umas mal-ajambradas calças compridas e nos sentíamos próximos da idade adulta, passávamos a sonhar em dar o fora. Queríamos ser como ele, o motorista. A chegada do caminhão era o corte epistemológico do sertão.

Tinha de acontecer. Um dia eu também ia subir num caminhão no rumo de uma cidade. E depois da primeira veio a segunda, a terceira, e outra e mais outra. Até chegar aqui, para contar a história.

Comecemos pelo aeroporto Santos Dumont, onde um dia um rapaz de vinte anos chegou, olhou a cidade de longe e foi embora. Eu me lembro: era uma bela tarde de janeiro, o mês do Rio. Céu de brigadeiro. O esplêndido azul de Machado de Assis. O 
azul demais de Vinícius de Moraes. Ano: 1961. O passageiro estava em trânsito. Vinha da Bahia com destino a São Paulo. Desceu aqui para fazer uma conexão, depois de cinco horas preso numa cadeira de uma geringonça ensurdecedora e vagarosa, relíquia aeronáutica da Segunda Grande Guerra. Um pau-de-arara do ar chamado curtis commander que, mal avistava uma pista de aterrissagem, ia baixando. Descer no Rio havia sido uma bênção. Para os seus ouvidos, suas pernas, seus olhos. Assim o vejo: olhando a cidade por trás dos vidros que o enjaulavam no saguão do aeroporto, enquanto aguardava a chamada para o embarque. Azul era também a cor do seu paletó. Ele estava convenientemente vestido para a sua primeira viagem de avião. Trajava até uma gravata vermelha sobre uma camisa branca. E os seus sapatos espelhavam, de tão bem lustrados. Numa das mãos, portava uma maleta com tudo o que possuía de seu, aos vinte anos - o que incluía meia dúzia de livros - além da roupa do corpo. Já que não podia sair, contentouse em olhar à distância a cidade que só conhecia de prosa e verso, cinema e canções. E tudo nela, que vinha dela, o fascinava. E dava medo. Imaginava-a fora da rota dos imigrantes, inatingível para principiantes. O Rio era a corte - dos sabidos e malandros. Suas artes e letras, sua natureza deslumbrante o atraíam. "Deus fez o mundo em sete dias, dos quais tirou um para fazer o Rio de Janeiro," dizia a voz de ouro de Luiz Jatobá, num documentário de Jean-Manzon. Mas a manchete do jornal comprado na banca do aeroporto o amedrontava. Era sobre uma operação de extermínio chamada de matamendigo. E ali estava ele, entre duas visões da cidade: uma sedutora, outra assustadora. Teve vontade de ficar. A chamada para o vôo o levou em frente. Tinha que ir para São Paulo. Assim estava escrito na sua passagem. Era um baiano do interior, um tímido roceiro, e estava indo para a locomotiva da nação, onde sempre haveria de caber mais um. Voltaria ao Rio um dia, para vê-lo de perto, entrar nele, conhecê-lo nas solas dos seus sapatos, se para tanto não lhe faltasse coragem. E algum preparo. O Rio não era uma cidade para capiaus, tabaréus da roça.

Trinta e cinco anos depois, um passageiro diário das linhas urbanas CopacabanaCentro, Centro-Copacabana vai retornar ao Santos Dumont. A pé. Para tentar descobrir o que foi mesmo o que aquele garoto interiorano viu - e se por um momento poderiam voltar a ser a mesma pessoa, ainda capaz de ver a cidade com um olhar de novidade.

(O Centro das Nossas Desatenções)

A história continua. Dia após dia a cidade abre espaço para a escrita dos que chegam, atraídos pelas suas luzes verdes, seu orgiástico futuro. Se tudo for uma ilusão, pouco importa. Procuraremos fazer disso uma ficção.

\section{SOCR}

14 - Légua \& mein: Revista de litrpatura e Diversidadr Cultural, v. 6, no 4, 2008 
Quando a cidade faz esquina com a escrita

When the city corners the writing

\section{RESUMO}

O autor delineia um grande mapa, de um possível passeio pelas mais famosas metrópoles do mundo, visualizando as "imagens do sonho" de Marco Polo, em O Livro das Maravilhas, as cidades invisíveis, de Ítalo Calvino, a metrópole de Paul Auster, em Cidade de Vidro, ou o Rio de Janeiro pintado por Machado de Assis, entre muitos outros - e esbarra na cidade partida do gueto que Paulo Lins descreve em Cidade de Deus.

Palavras-chave: cidade; escrita;fabulações

\section{ABSTRACT}

The author delineates a great map, of a possible meandering throughout the world's most famous metropoles, visualizing the "dream images" of Marco Polo, in his Book of Wonders, Italo Calvino's invisible cities, Paul Auster's metropolis in City of Glass, or Rio de Janeiro, as portrayed by Machado de Assis, amongst many other cityscapes — and encounters the divided city of the ghetto, described by Paulo Lins in City of God.

Key-words: city;writing;fabulations

Recebido: $10 / 08 / 2007$

Aprovado: $12 / 03 / 2008$

Antônio Torres, jornalista, redator de publicidade e escritor, estreou com o romance Um Cão Uivando nas para a lua, em 1972. Em seguida, publicou mais dez romances, sendo os mais recentes: O nobre sequestrador (2003) e Pelo fundo da agulha (2006). Durante anos, ministrou oficina de textos na UERJ, como escritor convidado. Recebeu o Prêmio Machado de Assis da Academia Brasileira de Letras, em 2000, pelo conjunto da obra. Este texto constitui uma conferência proferida na Universidade Federal do Rio de Janeiro - UFRJ, no encerramento do $2^{\circ}$ Congresso da Ciência da Literatura, dia 23/10/2002, sobre o espaço da cidade/ o espaço da escrita. 